\title{
Synthetic analysis of the efficacy of the S-net system in tsunami forecasting
}

\author{
Iyan E. Mulia ${ }^{1,2^{*}}$ (D) and Kenji Satake ${ }^{2}$
}

\begin{abstract}
The Seafloor Observation Network for Earthquakes and Tsunamis along the Japan Trench (S-net) is presently the world's largest network of ocean bottom pressure sensors for real-time tsunami monitoring. This paper analyzes the efficacy of such a vast system in tsunami forecasting through exhaustive synthetic experiments. We consider 1500 hypothetical tsunami scenarios from megathrust earthquakes with magnitudes ranging from Mw 7.7-9.1. We employ a stochastic slip model to emulate heterogeneous slip patterns on specified 240 subfaults over the plate interface of the Japan Trench subduction zone and its vicinity. Subsequently, the associated tsunamis in terms of maximum coastal tsunami heights are evaluated along the 50-m isobath by means of a Green's function summation. To produce tsunami forecasts, we utilize a tsunami inversion from virtually observed waveforms at the S-net stations. Remarkably, forecasts accuracy of approximately $99 \%$ can be achieved using tsunami data within an interval of 3 to 5 min after the earthquake (2-min length), owing to the exceedingly dense observation points. Additionally, we apply an optimization technique to determine the optimal combination of stations with respect to earthquake magnitudes. The results show that the minimum requisite number of stations to maintain the accuracy attained by the existing network configuration decreases from 130 to 90 when the earthquake size increases from Mw 7.7 to 9.1.
\end{abstract}

Keywords: Tsunami, Forecasting, Observing system, S-net

\section{Introduction}

As a response to the disastrous 2011 Tohoku-oki tsunami, the National Research Institute for Earth Science and Disaster Resilience (NIED) of Japan installed a largescale cabled seafloor observatory called the Seafloor Observation Network for Earthquakes and Tsunamis along the Japan Trench (S-net). S-net is an advancement of its predecessor the Deep Ocean-floor Network system for Earthquakes and Tsunamis (DONET) firstly deployed around the Nankai Trough in 2006 (Kaneda et al. 2015). Each observatory of S-net is strategically placed to address key scientific and practical issues related to earthquakes and tsunamis with the total coverage encompassing the entire focal region of the 2011 Tohoku-oki earthquake and its surrounding areas. The dense offshore observation stations of S-net would

\footnotetext{
*Correspondence: iyan.mulia@riken.jp

2 Earthquake Research Institute, The University of Tokyo, Tokyo, Japan

Full list of author information is available at the end of the article
}

enable timely and accurate tsunami forecasts, and thus effective warnings (Mulia and Satake 2020). Furthermore, combined with existing land-based instruments, S-net is expected to provide an additional and a more precise constraint for operational earthquake early warning and to study submarine earthquake processes and offshore seismicity (Kanazawa et al. 2016; Wallace et al. 2016; Nishikawa et al. 2019).

Although S-net is equipped with both ocean bottom pressure sensors and seismometers, here we focus our analysis only on the role and performance of the system in tsunami detection and forecasting using synthetic pressure sensor readings. Since the first establishment of S-net in 2016, the network has registered only a few tsunamis from: the 20 August 2016 off Sanriku earthquake characterized by a magnitude of $M \mathrm{w} 6.0$ (Kubota et al. 2020b), the 22 November 2016 off Fukushima earthquake with a magnitude of $M w 7.0$ (Kubota et al. 2020a), and a far-field event of the 8 September 2017 Chiapas, Mexico earthquake ( $M \mathrm{w}$ 8.1) (Mochizuki et al. 2018). 
The real tsunami events provide important insights on the viability of the observing systems, particularly that of instrumentation-related matters (Kubota et al. 2018). However, tsunamis are infrequent natural phenomena, and thus give limited access to comprehensively appraise the efficacy of tsunami observing systems against plausible various tsunami characteristics. Therefore, synthetic experiments are needed as a proxy or to complement the scarce tsunami data of the actual events.

The use of synthetic experiments conjointly with a data assimilation scheme through computer simulations has been commonly applied to assess the performance of prospective or even existing observing systems as operational forecast and methods evolve. Such an approach is termed as observing system simulation experiment, which is a well-established methodology in atmospheric and oceanographic fields (Hoffman and Atlas 2016; Fujii et al. 2019). In the tsunami case, synthetic experiments have also been applied to test either new forecasting methods or performance of observing systems. Several studies that are related to the utilization of S-net have been proposed (Tsushima et al. 2012a; Maeda et al. 2015; Yamamoto et al. 2016; Tanioka 2018, 2020; Fauzi and Mizutani 2020). Additionally, previous studies have demonstrated the benefit of cost-effective synthetic experiments aided by numerical simulations to identify optimal locations for placement of tsunami observation networks (Mulia et al. 2017a, 2019; Heidarzadeh et al. 2019; Navarrete et al. 2020; Wang et al. 2020). Here, we perform an analogous approach to analyze the capability of the existing S-net system in enhancing tsunami forecasts associated with a large number of hypothetical megathrust earthquakes in the study area. Additionally, we examine the proportion of stations that predominantly contribute to the overall forecast skill. The analysis would improve our understanding on the effect of station distribution in response to sources of different size and location. Furthermore, the result may also help the decision-making process should particular subsets of stations need to be altered in the future, or to set priority order for maintenance works. Overall, the numerous scenarios and optimization proposed in this study provide complementary information to the existing knowledge on the role of $\mathrm{S}$-net in tsunami forecasting.

\section{S-net configuration}

S-net consists of 150 seafloor observatories equipped with ocean bottom pressure sensors and seismometers (Kanazawa et al. 2016; Mochizuki et al. 2018). A study by Mizutani et al. (2020) demonstrated that a collocated pressure sensors and seismometers can be beneficial for processing of pressure data. All observatories are connected via submarine optical cables partitioned into six segments, with one or both ends of the respective segment linked with ground stations, to which the data are transmitted in real-time (see Fig. 1). The network uses in total a length of approximately $5800 \mathrm{~km}$ of cable connecting each station deployed in a variety of water depths ranging from 102 to $7830 \mathrm{~m}$ with a spatial interval between 30 and $60 \mathrm{~km}$, encompassing an area of $1000 \mathrm{~km} \times 300 \mathrm{~km}$. The ocean bottom pressure sensor of S-net is based on the Paroscientific Digiquartz pressure sensor capable to output the data at $1 \mathrm{kHz}$ frequency (Kanazawa et al. 2016). A similar device has also been used, though possibly of different versions, by other ocean observation networks (Polster et al. 2009), including the Deep-ocean Assessment and Reporting of Tsunamis developed by NOAA's Pacific Marine Environmental Laboratory (Yilmaz et al. 2004).

As a regional observing system, S-net spatial coverage is astounding and considerably wider than the previously established DONET system. Besides the focal region of the 2011 Tohoku-oki earthquake, the design of S-net spatial distribution is also aimed at smaller events, so that at least one observatory is expected to exist in the focal region of $M \mathrm{w} 7.5$ earthquakes occurring in the targeted seismogenic zone (Kanazawa et al. 2016). Furthermore, the outer trench segment located in the outer-rise region would be beneficial for real-time tsunami detections (Mulia et al. 2019), as the wave propagates faster in deep water. The tsunamis associated with potential outer-rise earthquakes near the Japan Trench have been evaluated through numerical simulations by Baba et al. (2020). However, this study is limited to account for tsunamis generated by great interplate earthquakes only.

\section{Stochastic slip model}

We discretize the plate interface of the Japan Trench subduction zone obtained from the SLAB 2 model (Hayes et al. 2018) with the downdip limit of $40 \mathrm{~km}$, into 240 curvilinear grids with approximate sizes varying from $\sim 20$ to $\sim 40 \mathrm{~km}^{2}$ as shown in Fig. 2. We then apply a method by Mai and Beroza (2002) to characterize complexity of earthquake slip represented by a spatial random field according to a von Karman autocorrelation function. We consider the range of earthquake magnitudes of $M \mathrm{w}$ 7.7-9.1 with a magnitude interval of 0.1. In our study, the random slip is initially calculated on a rectangular fault of $1 \mathrm{~km} \times 1 \mathrm{~km}$ grid spacing with length and width estimated using a magnitude-area scaling relation (Wells and Coppersmith 1994). Then, the result is interpolated and projected into the specified curvilinear grids of subfaults with arbitrary rupture area to facilitate the tsunami Green's function computation. The slip on each subfault is assumed to be constant and obtained by applying a bilinear interpolation without altering the mean slip, 


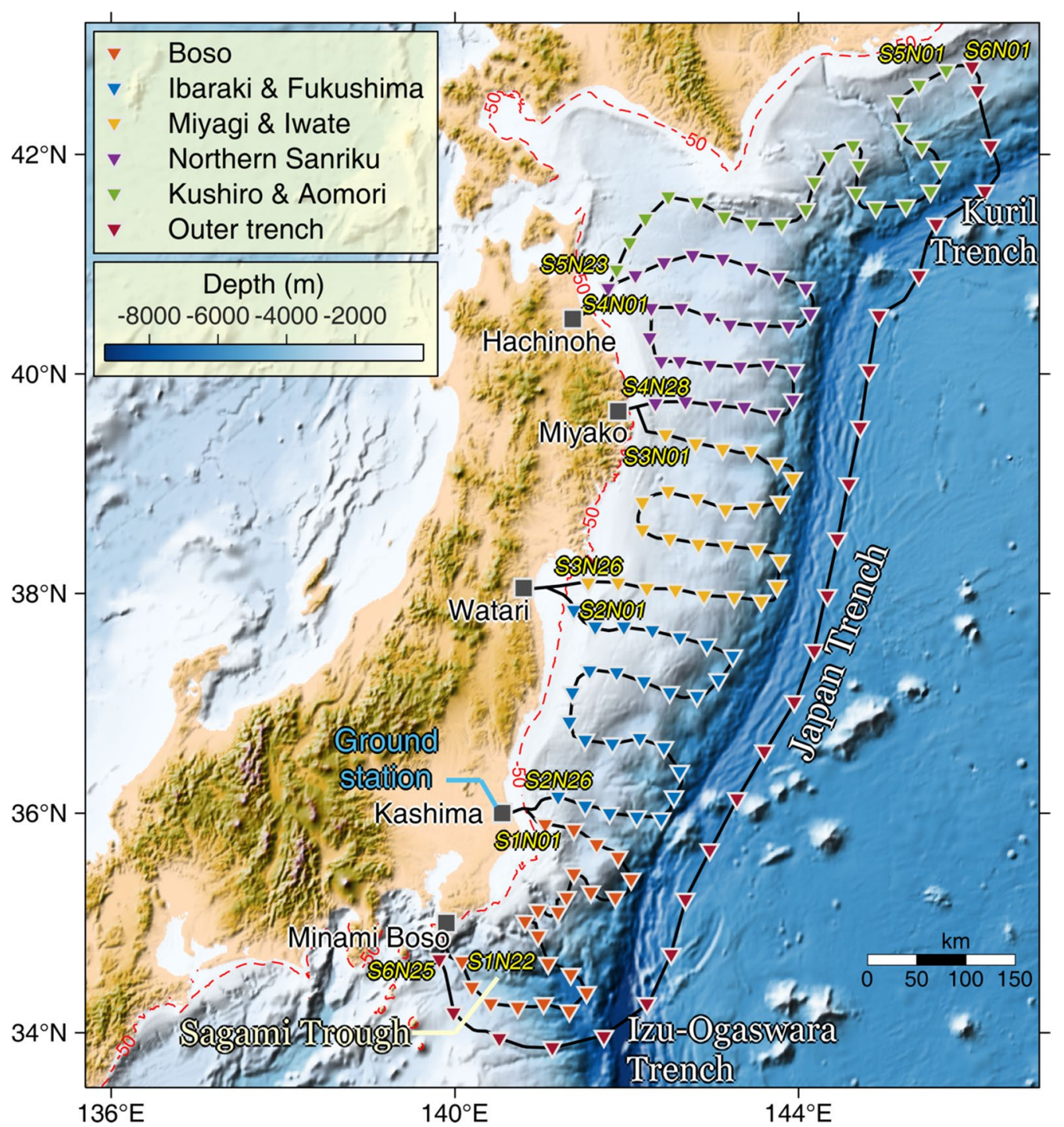

Fig. 1 Bathymetry of study area and locations of S-net. Station names at both ends of each segment are annotated. The red dashed contour lines mark the 50-m isobath

hence preserving the moment magnitude of the interpolated sample. The mean slip for the specified magnitude range is shown in Table 1. A kinematic rupture process can be incorporated in the stochastic slip model (Mai et al. 2005), which would affect the tsunami nucleation, particularly for extremely large earthquakes (Satake et al. 2013; Goda et al. 2014). In this study, however, we neglect such a detailed modeling as we emphasize on a large number of earthquake scenarios. Moreover, the contribution of the kinematic component for near-field tsunami hazards is minimum (Williamson et al. 2019).

Once the random slip of the respective magnitude is generated, we calculate the sea surface displacement using a triangular dislocation in a half-space proposed by Nikkhoo and Walter (2015), assuming a rake angle of $90^{\circ}$, an instantaneous deformation, and a long wave approximation. The advantage of such a method is that the geometry of the seismogenic zone or the curvature of the trench can easily be approximated, which is more appropriate than a standard rectangular fault model for large earthquake events (Sepúlveda et al. 2017). Therefore, each rectilinear grid consists of two triangular meshes with the same slip amount (Additional file 1: Figure S1). Examples of the random slip and its corresponding displacement for earthquakes of magnitude $M w$ 7.7, 8.4, and 9.1 are shown in Fig. 2. 


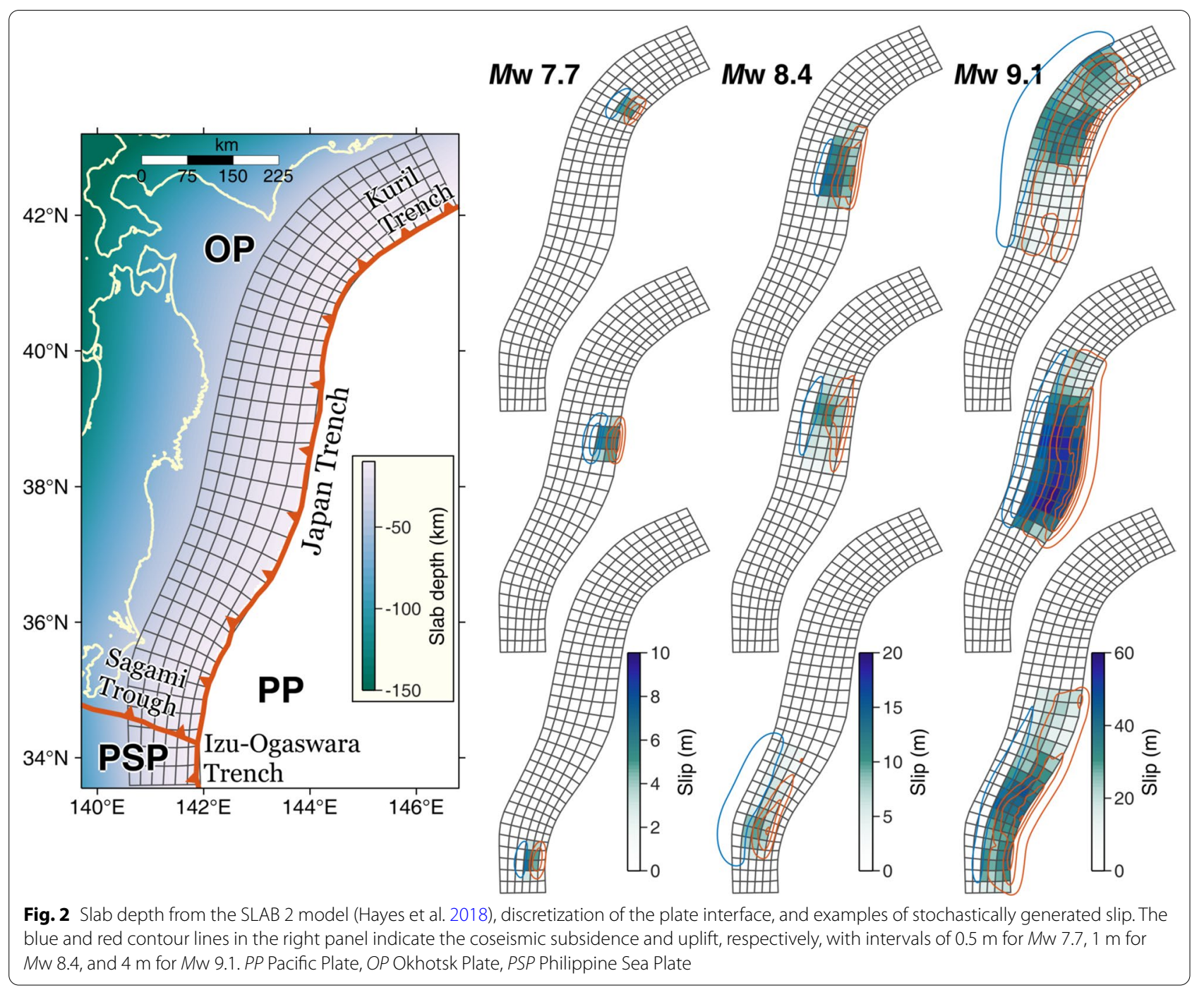

\section{Virtual observations and number of samples}

To efficiently generate a large number of tsunamis virtually observed at S-net stations, we utilize a tsunami Green's function summation leveraging the linear superposition theory (Satake 1987). We simulate tsunamis from the 240 subfaults with 1-m slip by solving the linear shallow water equations using a numerical tsunami simulation code called JAGURS (Baba et al. 2015, 2017). We set the simulation time at $5 \mathrm{~h}$ and the numerical grid size at 1 arc minute with the bathymetry data resampled from the GEBCO 30 arc-second bathymetric grid (Weatherall et al. 2015). The virtual tsunami observations are then obtained by applying the precalculated Green's function to the stochastically generated slip described in Sect. 3 . Since S-net observes pressure changes instead of sea surface fluctuations, the pressure readings are affected by the coseismic permanent seafloor displacement if the observatories are located inside the source region (Tsushima et al. 2012b; Tanioka 2018). Therefore, similar to previous studies (Maeda et al. 2015; Inazu et al. 2016; Mulia et al. 2017b), we subtract the simulated waveforms at S-net stations by the corresponding initial displacement at the station locations. This will cause a constant offset or bias in the pressure readings indicating the coseismic permanent seafloor displacement effect. We then add a random Gaussian noise with a maximum amplitude of $1 \mathrm{~cm}$, considering the ability of bottom pressure sensors in detecting sub-centimeter tsunamis (Wang et al. 2019; Kubota et al. 2020b).

We perform a statistical analysis to estimate the required number of samples at each earthquake magnitude interval, reflecting the expected optimum variance of the corresponding tsunamis. The analysis aims at efficiently determining the number of samples, which suggests that incorporation of more scenarios than the required number will no longer contribute to the 
Table 1 Calculation of total number of samples and mean slip of each magnitude

\begin{tabular}{llll}
\hline No. & Mw & Mean slip $(\mathrm{m})$ & $\begin{array}{c}\text { Number of samples at } \\
\text { each magnitude }\end{array}$ \\
\hline 1 & 7.7 & 3.3 & 150 \\
2 & 7.8 & 3.9 & 143 \\
3 & 7.9 & 4.3 & 136 \\
4 & 8.0 & 5.0 & 129 \\
5 & 8.1 & 5.3 & 121 \\
6 & 8.2 & 5.8 & 114 \\
7 & 8.3 & 6.7 & 107 \\
8 & 8.4 & 7.6 & 100 \\
9 & 8.5 & 8.7 & 93 \\
10 & 8.6 & 9.1 & 86 \\
11 & 8.7 & 11.2 & 79 \\
12 & 8.8 & 13.0 & 71 \\
13 & 8.9 & 13.4 & 64 \\
14 & 9.0 & 17.0 & 57 \\
15 & 9.1 & 20.2 & 50 \\
Total scenarios & & & 1500 \\
\hline
\end{tabular}

variability of coastal tsunami heights, thus is redundant. Like the virtually observed waveforms at S-net, we also store tsunami waveforms at specified coastal points along the $50-\mathrm{m}$ isobath for validation purposes. However, we only consider the maximum elevation of the first three waves where the highest tsunami wave height is typically registered, termed as coastal tsunami heights. Subsequently, the arrival time is defined at the identified peak. We apply statistical measure that shows the extent of variability of samples around the mean using a coefficient of variation, $\mathrm{CV}=\sigma / \mu$, where $\sigma$ is the standard deviation and $\mu$ is the mean of tsunami heights at all coastal points and considered samples (Mulia et al. 2020). At each magnitude interval, we calculate the coefficient of variation at every increment of samples from 2 to 200 as shown in Fig. 3. As expected, the variability increases with the decrease of magnitude owing to the larger probability of location for smaller earthquakes. For instance, the variation of coastal tsunami heights due to $M \mathrm{w} 7.7$ earthquakes is quite stable if more than 150 samples are used. This stable condition is attained with a smaller number of samples for larger earthquakes. By visual inspection, we draw a straight line connecting a point at curves of each magnitude, beyond which the fluctuation of coefficient of variation is less prominent (see Fig. 3). This line marks the requisite number of earthquake scenarios at each magnitude, which is summarized in Table 1 . The total number of scenarios considered in this study is 1,500. Figure 4 shows examples of coastal tsunami heights and arrival times at the specified coastal points by earthquakes of

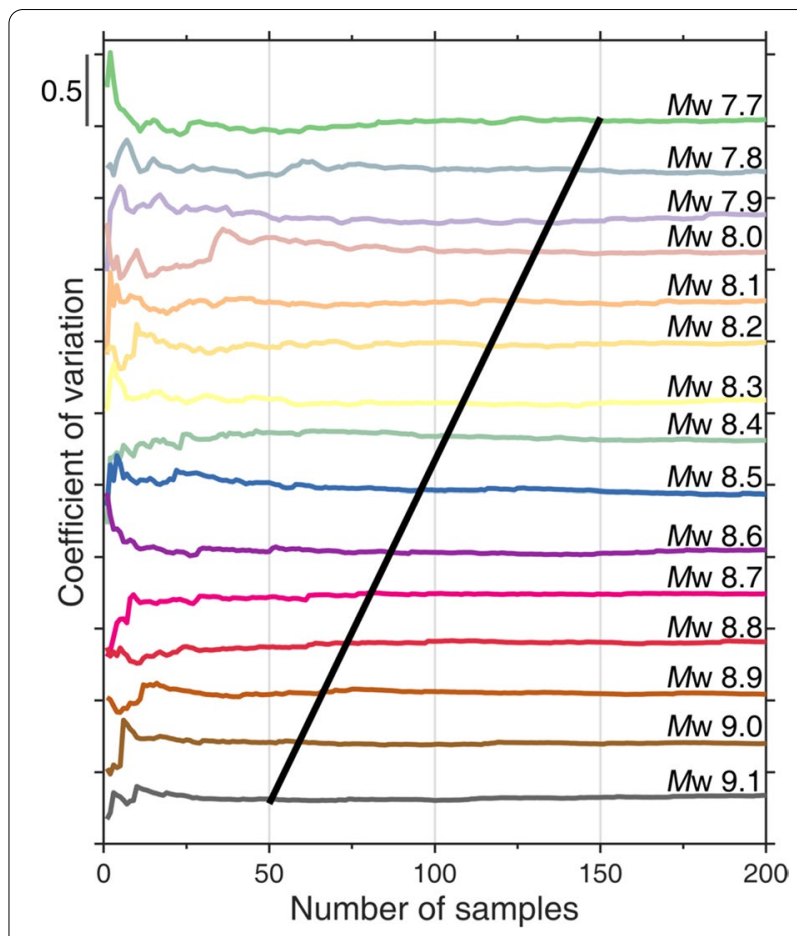

Fig. 3 Coefficient of variation of coastal tsunami heights. The black line indicates the required number of samples at each magnitude

magnitude $M w$ 7.7, 8.4, and 9.1 in conjunction with complementary statistical properties in terms of mean and percentiles $\left(10^{\text {th }}\right.$ and $\left.90^{\text {th }}\right)$.

\section{Tsunami forecasting}

We employ a tsunami waveform inversion method to forecast coastal tsunami heights (Mulia et al. 2019), which is an extension of the original study applied to characterize the inducing earthquake (Satake 1987, 1989; Gusman et al. 2016). Unlike the source characterization, in forecasting, the inversion time window is started immediately from the earthquake origin time to a certain instant for an effective warning dissemination. The forecasts can then be obtained by applying the inverted parameters (slip amount on the 240 faults, in our study) from observed waveforms (at S-net stations) to the synthetic waveforms or precalculated Green's function at locations of interest, which in our case are the coastal points indicated in Fig. 5. Our tsunami waveform inversion takes into account the effect of permanent seafloor displacement as suggested by Tsushima et al. (2012b). However, another issue that may arise in the bottom pressure data is the interference of a low-frequency component of seismic waves that are difficult to distinguish from tsunami signals, particularly at stations near the source region (Saito and Kubota 2020). A proper way to synthesize such occurrences was demonstrated by Saito 

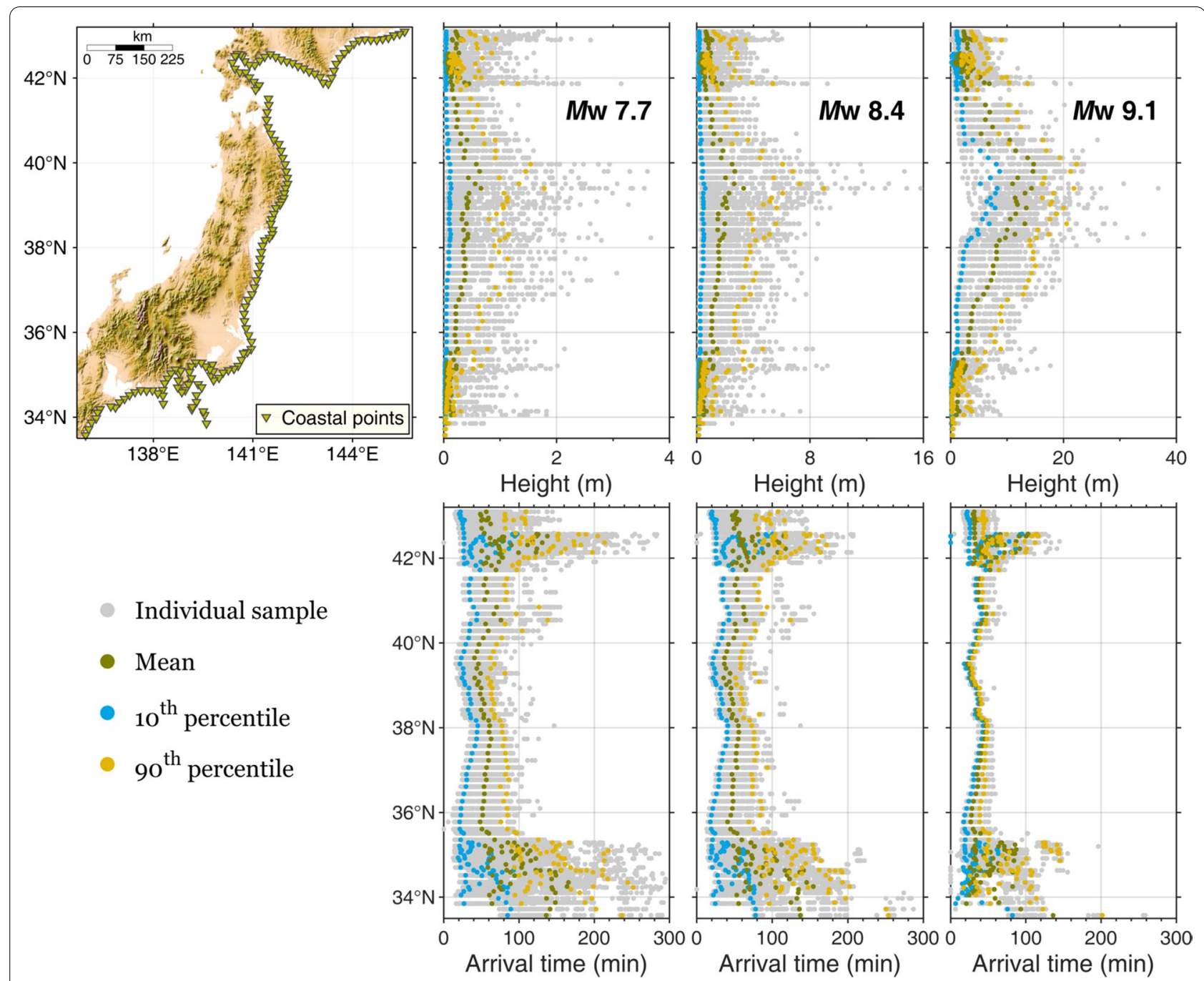

Fig. 4 Simulated coastal tsunami heights and arrival times at locations marked in the top left panel associated with all samples of magnitude $\mathrm{Mw}$ 7.7, Mw 8.4, and Mw 9.1

and Tsushima (2016), but it is beyond the scope of this paper. Here, we simply omit the first 3 min of observed waveforms in the inversion analysis following a study by Inazu et al. (2016). Therefore, our inversion time window is started at $3 \mathrm{~min}$ after the earthquake origin time. The forecasted tsunami heights are then evaluated against the reference values described in Sect. 4, using an accuracy score in percentage (Tsushima et al. 2009).

Figure 5 shows examples of forecast accuracies for coastal tsunami heights associated with earthquakes of magnitude $\mathrm{Mw} 7.7,8.4$, and 9.1, at 12 locations of interest. These locations are selected merely for visual clarity. Note that the accuracy is based on the mean accuracy of samples for the respective magnitude as tabulated in Table 1. We perform the tsunami waveform inversion with various time windows: $3-5 \mathrm{~min}$, 3-7.5 min, 3-10 min, 3-12.5 min, and 3-15 min. It is not surprising that, in general, more data exponentially improves the accuracy. Furthermore, Fig. 5 indicates that forecast accuracy for larger earthquakes is better than the smaller ones, because tsunamis of large earthquakes are registered at more S-net stations. Another plausible explanation for the reduction of accuracy associated with small earthquakes is the decrease of tsunami signal-to-noise ratio, as we fix the noise level. However, further sensitivity analyses should be conducted to provide quantitative information supporting the notion. The least accurate result of the smallest considered magnitude of $M \mathrm{w} 7.7$ yields a mean accuracy of $99 \%$ by using only tsunami data from 3 to 5 min after the earthquake. 


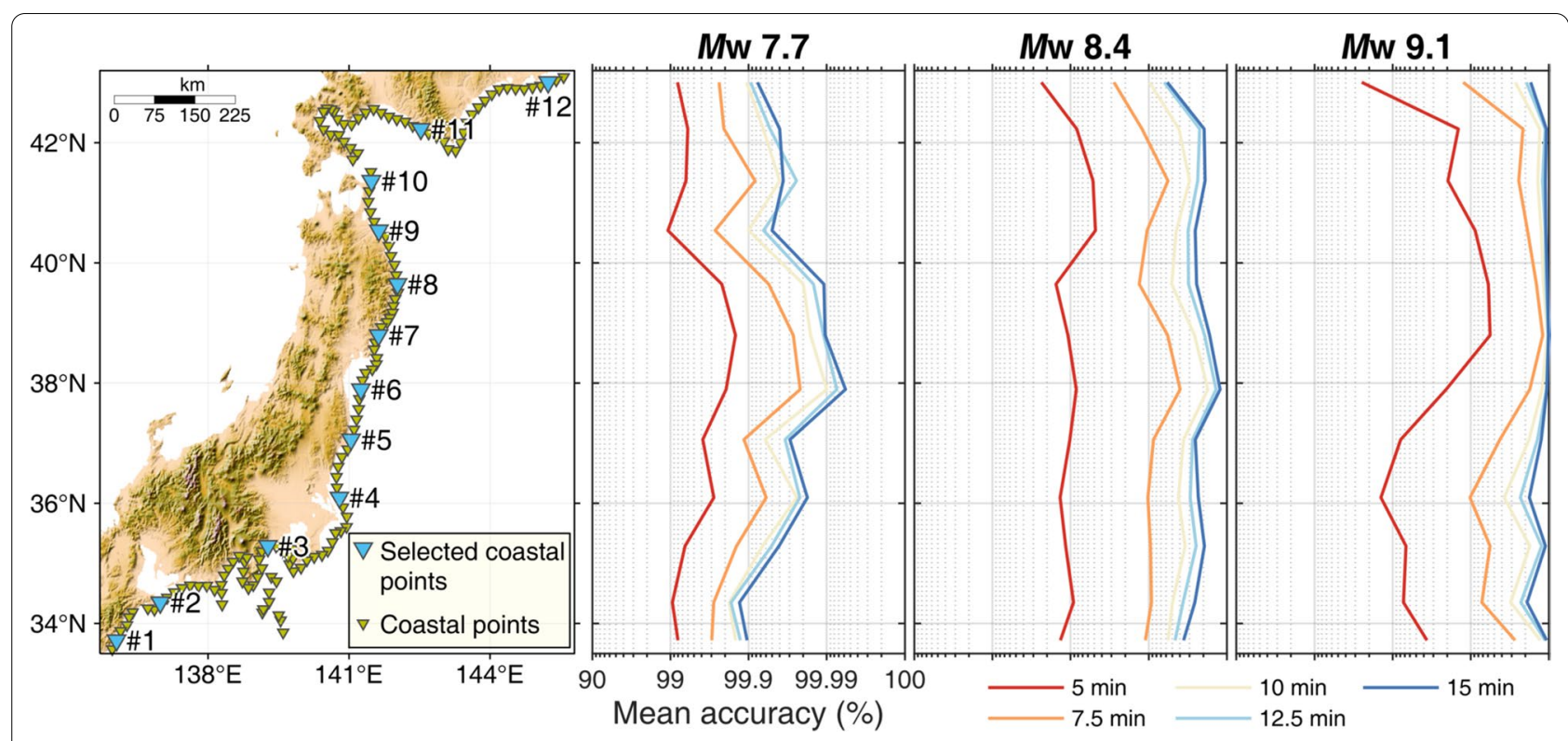

Fig. 5 Forecast accuracies at 12 coastal points indicated in the left panel for magnitude of $M w$ 7.7, Mw 8.4, and $M w$ 9.1, using various inversion time windows

This short time window interval is well-compensated by the exceedingly dense observation points. Therefore, the dynamics of the tsunami in the early stages related to the source process, where the most energetic part of the offshore tsunami normally occurs (Mulia et al. 2017a) can be well-captured, and thus in turn leads to accurate forecasts.

Forecasting accuracies by S-net indicated in this study would be different for far-field events or source areas beyond the specified seismogenic region. However, the vast coverage of S-net should be able to protect the same coastal locations from various incident tsunami wave directions. Moreover, forecasting far-field tsunamis is not as challenging as for near-field events for which the tsunami lead time is critical. Even though our results show that larger tsunamis can be forecasted more accurately than the smaller ones, such large source areas on the other hand result in extremely short lead times as depicted in Fig. 4. Therefore, lead time information must be regarded as one of the crucial factors in tsunami forecasting, for it would determine the effectiveness of observing and warning systems (Williamson and Newman 2018; Mulia et al. 2019).

\section{Optimized stations distribution}

We adopt an optimization scheme similar to a previous study (Mulia et al. 2019) to determine the optimal combination of stations that give the smallest forecast error. During the optimization, the combinatorial search of optimal observation sets is performed by iteratively computing the tsunami waveform inversion. For simplification, here we use one inversion time window of 3-5 min only. We apply the optimization to three groups of samples based on magnitude ranges of $M \mathrm{w}$ 7.7-8.1, $M \mathrm{w} \mathrm{8.2-8.6,} \mathrm{and} M \mathrm{w}$ 8.7-9.1. This experiment aims at further understanding the effect of station distribution and quantity to the forecast accuracy with respect to different earthquake magnitudes. We set the number of stations, which is equivalent to the number of decision variables in the optimization, of 10 to 140 with an interval of 10 . The forecast results using 150 stations are taken from the previous stage in Sect. 5.

The optimization results are shown in Fig. 6. In general, more stations lead to better accuracy for all specified earthquake magnitude ranges. However, it is apparent that tsunamis from smaller earthquakes are more difficult to forecast, which further confirm the previous results in Sect. 5. For example, using 10 stations, the lowest mean accuracy at one or more of the considered coastal points is approximately $50 \%$ for the magnitude range of $M \mathrm{w} 7.7-8.1$, whereas are $65 \%$ and $78 \%$ for the $M \mathrm{w}$ 8.4-8.6 and $M \mathrm{w}$ 8.7-9.1, respectively. Consequently, smaller earthquake magnitudes or tsunami sources require more stations to attain a level of forecast accuracy comparable to larger earthquakes. This is clearly indicated in Fig. 6, where a level of mean accuracy of approximately $99 \%$ can be achieved using 130 stations for $M \mathrm{w} 7.7-8.1,110$ stations for $M \mathrm{w} 8.4-$ 8.6, and 90 stations for $M w$ 8.7-9.1. The corresponding 


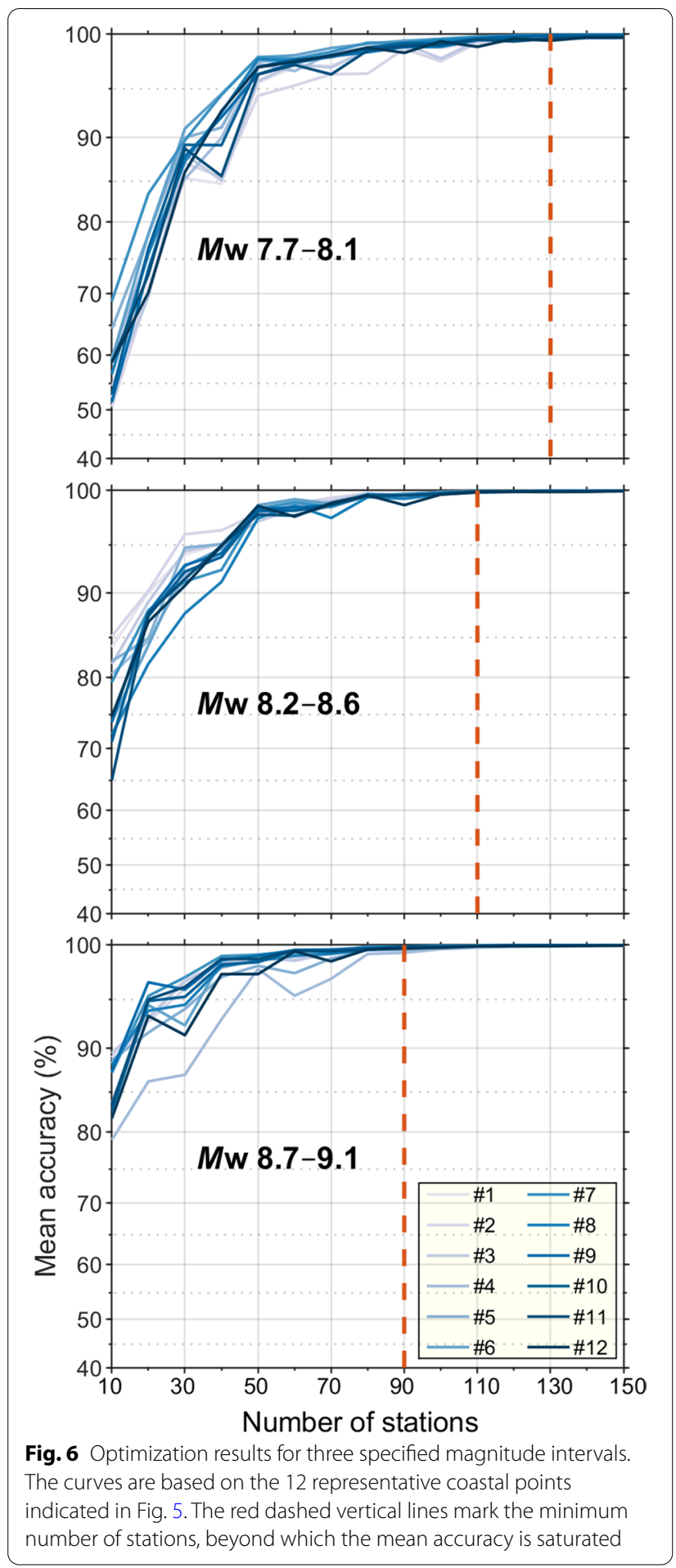

optimized station distribution for the three magnitude ranges is plotted in Fig. 7. The figure evinces that the optimization tends to spread the stations sufficiently wide enough to gain the appropriate azimuthal coverage.

\section{Discussion}

It is worth noting that regardless of the earthquake magnitudes, significant maximum coastal tsunami heights predominantly occur between the latitude of $38^{\circ} \mathrm{N}-40^{\circ} \mathrm{N}$ (see Fig. 4). The same occurrence was also shown by the previous studies (e.g., Fukutani et al. 2015; Murphy et al. 2016). Moreover, Murphy et al. (2016) compared their modeled coastal tsunami heights against wave heights and run-ups from three historical events of the 2011 Tohoku-oki earthquake, the 1993 and 1986 Sanriku earthquakes, which also produced higher tsunamis within approximately the same latitude range. This may imply particular characteristics of the coastal areas responsible for the amplification of tsunamis. However, the arrival time plots (Fig. 4) suggest that large tsunamis at these locations arrive earlier (within $\sim 20 \mathrm{~min}$ ) compared to the neighboring coastal points on the mainland, which may also be an indication of coastal point locations being close to the seismogenic plate interface. Nonetheless, the highly energetic tsunamis contribute to the relatively more accurate forecasts than other areas (Fig. 5), which is likely attributed to the S-net segments of Miyagi and Iwate and Northern Sanriku.

We note that accuracies stated in this study may not reflect the actual operational forecast performance. First, mechanical issues are commonly encountered in practice that would deteriorate the data quality (Kubota et al. 2018), and hence the corresponding forecast accuracy. Second is likely due to the oversimplification in synthesizing real pressure waveforms. However, even an advanced approach to more realistically mimic the pressure data, as demonstrated by Saito and Tsushima (2016), also proved that the dense S-net stations substantially contribute to the forecast accuracy. Unfortunately, their study was applied to a limited number of scenarios. A study to evaluate the S-net system by Inoue et al. (2019) considered more hypothetical earthquake scenarios, but their objective was to characterize the source rather than forecasting. Last is related to the forecasting algorithm, in which tsunami forecasting methods by tsunami waveform inversion typically use auxiliary basis functions (e.g., Gaussian shape, cosine-tapered function) instead of a fault model. The structure of the basis function would to some extent affect the accuracy of the forecasted coastal tsunami heights. Apart from that, other forecasting methods may also yield different level of accuracies (Hadihardaja et al. 2011; Mulia et al. 2016; Yamamoto et al. 2016; Lee et al. 2020).

Notwithstanding the aforementioned limitations, this study is necessary to appraise and highlight the benefit of utilizing the dense offshore tsunami observation network for tsunami forecasting, which are proven and tested against numerous plausible hypothetical scenarios. 


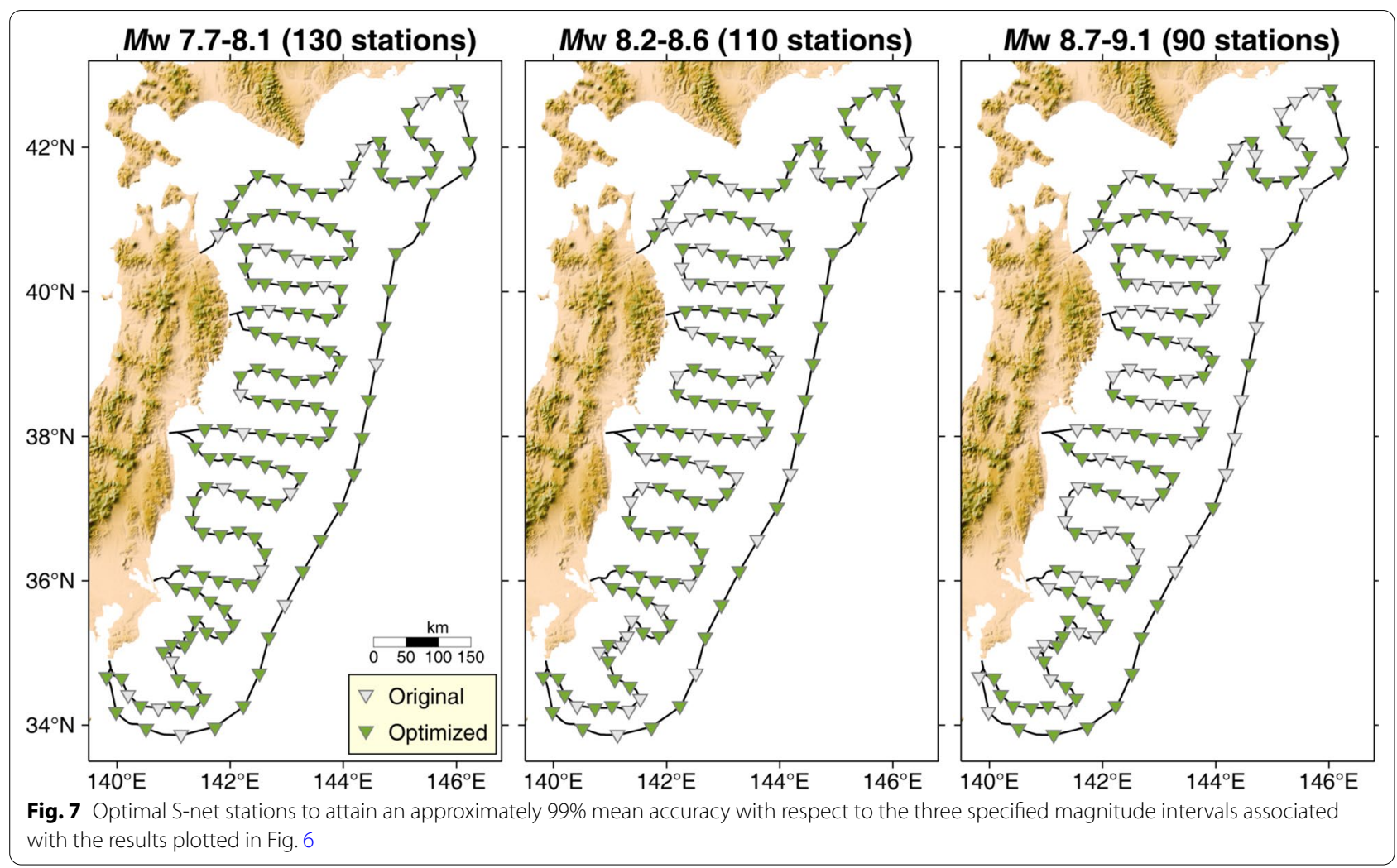

A supplementary example using a single hypothetical tsunami event generated by an earthquake of magnitude Mw 7.7 is presented in Additional file 1: Figure S2 to S4. The figures clearly show that the same length of data (3-5 min window) at considerably less number of stations results in a poor forecast performance, thus the existence of S-net has greatly improved the skill of coastal tsunami height forecasts in the study area. The experiment also shows that the optimized 130 stations can produce a comparable accuracy to that of all $150 \mathrm{~S}$-net stations. Therefore, by applying the optimization technique, we are able to reveal the contribution of subsets of S-net stations in response to tsunamis of different sizes. The results shown in Fig. 6 can also be interpreted as the limit of requisite number of stations for different magnitude ranges, beyond which the accuracy level is saturated. With such information one can determine which stations should be given priority in sustaining accurate tsunami forecasts. However, the nature of our optimization allows for exclusion of stations selected for larger earthquakes when being optimized for smaller events and vice versa, hence the result should be viewed with some caution. Furthermore, since we consider near-field events only, the optimized station distribution may not be relevant for far-field tsunamis or source areas outside the specified seismogenic region. The list of subsets of optimal
S-net stations with respect to the specified magnitude ranges depicted in Fig. 7 can be found in Additional file 2: Table S1.

\section{Conclusion}

We have comprehensively evaluated the performance of the S-net system in enhancing the tsunami forecasting skill in the study area by utilizing a large number of plausible hypothetical scenarios associated with megathrust events, occurring on the Japan Trench subduction zone and its vicinity. Our study demonstrates that the vast coverage of S-net significantly contributes to the accuracy of forecasted coastal tsunami heights along the Pacific coast of Japan. Based on the proposed synthetic experiments, it is evident that the dense offshore tsunami observation network of $\mathrm{S}$-net is capable of producing the desired forecast performance using relatively short tsunami data, which is difficult to achieve when only a few stations are available. However, in the real cases, various technical issues that may cause the deterioration of data quality should be anticipated. Additionally, we also determine the contribution of subsets of S-net stations to the forecast accuracy corresponding to various earthquake magnitude ranges through an optimization approach, which in general suggests that more observation points are needed for smaller earthquake-induced tsunamis. 
Furthermore, the results indicate the preeminent stations of S-net that should be sustained to ensure accurate tsunami forecasts.

\section{Supplementary Information}

The online version contains supplementary material available at https://doi. org/10.1186/s40623-021-01368-6.

Additional file 1: Figure S1. Meshes for the triangular dislocation in a half-space model to calculate the displacement (left panel). Rectilinear grids where the final slip is calculated (right panel). Contours indicate plate interface depth. Figure S2. Tsunami forecasting using 6 stations. The top left panel shows virtually observed (reference) vs forecasted waveforms at the sample stations indicated in the bottom left panel including the reference slip, and the length of tsunami data used for the inversion analysis marked by light yellow areas. Top right panel shows reference vs forecasted waveforms at the 12 coastal points shown in the bottom right panel including the inverted slip. Figure S3. Tsunami forecasting using all S-net stations. The top left panel shows virtually observed (reference) vs forecasted waveforms at the nearest stations to the source indicated in the bottom left panel including the reference slip, and the length of tsunami data used for the inversion analysis marked by light yellow areas. Top right panel shows reference vs forecasted waveforms at the 12 coastal points shown in the bottom right panel including the inverted slip. Figure S4. Tsunami forecasting using optimized 130 S-net stations. The top left panel shows virtually observed (reference) vs forecasted waveforms at the nearest stations to the source indicated in the bottom left panel including the reference slip, and the length of tsunami data used for the inversion analysis marked by light yellow areas. Top right panel shows reference vs forecasted waveforms at the 12 coastal points shown in the bottom right panel including the inverted slip.

Additional file 2: Table S1. Optimized S-net stations distribution with respect to the specified magnitude ranges.

\section{Abbreviations}

DONET: Deep Ocean-floor Network system for Earthquakes and Tsunamis; NIED: National Research Institute for Earth Science and Disaster Resilience; NOAA: National Oceanic and Atmospheric Administration; S-net: Seafloor Observation Network for Earthquakes and Tsunamis along the Japan Trench; tFISH: Tsunami Forecasting based on Inversion for initial sea-Surface Height.

\section{Acknowledgements}

The method to generate stochastic slip realizations is available at (http:// equake-rc.info/cers-software/rupgen/). The authors would like to thank the editor and two anonymous reviewers for their comments and suggestions to improve the quality of the paper.

\section{Authors' contributions}

IEM performed numerical and statistical analyses, and drafted the manuscript. KS contributed to the interpretation of results and writing the manuscript. All authors read and approved the final manuscript.

\section{Funding}

Not applicable.

\section{Availability of data and materials}

Bathymetric data are based on GEBCO 30 arc-second grid available at https ://www.gebco.net/. Locations of S-net stations are obtained from the NIED website https://www.bosai.go.jp/inline/gallery/index.html. The SLAB 2 model is downloaded from https://github.com/usgs/slab2.

\section{Competing interests}

The authors declare that they have no competing interests.

\section{Author details}

${ }_{1}^{1}$ Prediction Science Laboratory, RIKEN Cluster for Pioneering Research, Kobe, Japan. ${ }^{2}$ Earthquake Research Institute, The University of Tokyo, Tokyo, Japan.
Received: 4 September 2020 Accepted: 22 January 2021

Published online: 04 February 2021

\section{References}

Baba T, Takahashi N, Kaneda Y et al (2015) Parallel implementation of dispersive tsunami wave modeling with a nesting algorithm for the 2011 Tohoku Tsunami. Pure Appl Geophys 172:3455-3472. https://doi.org/10.1007/ s00024-015-1049-2

Baba T, Allgeyer S, Hossen J et al (2017) Accurate numerical simulation of the far-field tsunami caused by the 2011 Tohoku earthquake, including the effects of Boussinesq dispersion, seawater density stratification, elastic loading, and gravitational potential change. Ocean Model 111:46-54. https://doi.org/10.1016/j.ocemod.2017.01.002

Baba T, Chikasada N, Nakamura Y et al (2020) Deep investigations of outer-rise tsunami characteristics using well-mapped normal faults along the Japan Trench. J Geophys Res Solid Earth 125:e2020JB020060. https://doi. org/10.1029/2020JB020060

Fauzi A, Mizutani N (2020) Potential of deep predictive coding networks for spatiotemporal tsunami wavefield prediction. Geosci Lett 7:20. https:// doi.org/10.1186/s40562-020-00169-1

Fujii Y, Remy E, Zuo H et al (2019) Observing system evaluation based on ocean data assimilation and prediction systems: on-going challenges and future vision for designing/supporting ocean observational networks. Front Mar Sci. https://doi.org/10.3389/fmars.2019.00417

Fukutani Y, Suppasri A, Imamura F (2015) Stochastic analysis and uncertainty assessment of tsunami wave height using a random source parameter model that targets a Tohoku-type earthquake fault. Stoch Environ Res Risk Assess 29:1763-1779. https://doi.org/10.1007/s00477-014-0966-4

Goda K, Mai PM, Yasuda T, Mori N (2014) Sensitivity of tsunami wave profiles and inundation simulations to earthquake slip and fault geometry for the 2011 Tohoku earthquake. Earth Planet Space 66:1-20. https://doi. org/10.1186/1880-5981-66-105

Gusman AR, Mulia IE, Satake K et al (2016) Estimate of tsunami source using optimized unit sources and including dispersion effects during tsunami propagation: The 2012 Haida Gwaii earthquake. Geophys Res Lett. https ://doi.org/10.1002/2016GL070140

Hadihardaja IK, Latief H, Mulia IE (2011) Decision support system for predicting tsunami characteristics along coastline areas based on database modelling development. J Hydroinform. https://doi.org/10.2166/hydro.2010.001

Hayes GP, Moore GL, Portner DE et al (2018) Slab2, a comprehensive subduction zone geometry model. Science 362(6410):58-61. https://doi. org/10.1126/science.aat4723

Heidarzadeh M, Wang Y, Satake K, Mulia IE (2019) Potential deployment of offshore bottom pressure gauges and adoption of data assimilation for tsunami warning system in the western Mediterranean Sea. Geosci Lett. https://doi.org/10.1186/s40562-019-0149-8

Hoffman RN, Atlas R (2016) Future observing system simulation experiments. Bull Am Meteorol Soc 97:1601-1616. https://doi.org/10.1175/BAMSD-15-00200.1

Inazu D, Waseda T, Hibiya T, Ohta Y (2016) Assessment of GNSS-based height data of multiple ships for measuring and forecasting great tsunamis. Geosci Lett. https://doi.org/10.1186/s40562-016-0059-y

Inoue $M$, Tanioka Y, Yamanaka Y (2019) Method for near-real time estimation of Tsunami sources using ocean bottom pressure sensor network (S-net). Geoscience. https://doi.org/10.3390/geosciences9070310

Kanazawa T, Uehira K, Mochizuki M, et al (2016) S-net project, cabled observation network for earthquake and tsunamis. In: Suboptic2016. p WE2B3

Kaneda Y, Kawaguchi K, Araki E et al (2015) Development and application of an advanced ocean floor network system for megathrust earthquakes and tsunamis. SEAFLOOR OBSERVATORIES: A New Vision of the Earth from the Abyss. Springer, Berlin Heidelberg, Berlin, Heidelberg, pp 643-662

Kubota T, Chikasada NY, Tsushima H, Suzuki W (2020a) Tsunami analysis using the S-net pressure gauge records during the Mw 7.0 Off-Fukushima earthquake on 22 Novenver 2016 to reduce the effects of tsunami-irrelevant pressure components. Abstr. HDS08-11 Present. JpGU-AGU Jt. Meet. 2020, virtual Meet. Japan, 12-16 July 2020

Kubota T, Saito T, Suzuki W (2020) Millimeter-scale tsunami detected by a wide and dense observation array in the deep ocean: fault modeling of 
an Mw 6.0 interplate earthquake off Sanriku NE Japan. Geophys Res Lett 47:e2019GL085842. https://doi.org/10.1029/2019GL085842

Kubota T, Suzuki W, Nakamura T et al (2018) Tsunami source inversion using time-derivative waveform of offshore pressure records to reduce effects of non-tsunami components. Geophys J Int 215:1200-1214. https://doi. org/10.1093/GJ/GGY345

Lee JW, Irish JL, Weiss R (2020) Rapid prediction of alongshore run-up distribution from near-field tsunamis. Nat Hazards. https://doi.org/10.1007/s1106 9-020-04209-z

Maeda T, Obara K, Shinohara M et al (2015) Successive estimation of a tsunami wavefield without earthquake source data: a data assimilation approach toward real-time tsunami forecasting. Geophys Res Lett 42:7923-7932. https://doi.org/10.1002/2015GL065588

Mai PM, Beroza GC (2002) A spatial random field model to characterize complexity in earthquake slip. J Geophys Res Solid Earth 107(B11):2308. https ://doi.org/10.1029/2001jb000588

Mai PM, Spudich P, Boatwright J (2005) Hypocenter locations in finitesource rupture models. Bull Seismol Soc Am 95:965-980. https://doi. org/10.1785/0120040111

Mizutani A, Yomogida K, Tanioka Y (2020) Early tsunami detection with nearfault ocean-bottom pressure gauge records based on the comparison with seismic data. J Geophys Res Ocean 125:e2020JC016275. https://doi. org/10.1029/2020JC016275

Mochizuki M, Uehira K, Kanazawa T et al (2018) S-net project: Performance of a large-scale seafloor observation network for preventing and reducing seismic and tsunami disasters. 2018 Ocean - MTS/IEEE Kobe TechnoOceans. Ocean - Kobe 2018:1-4. https://doi.org/10.1109/OCEANSKOBE .2018 .8558823

Mulia IE, Asano T, Nagayama A (2016) Real-time forecasting of near-field tsunami waveforms at coastal areas using a regularized extreme learning machine. Coast Eng. https://doi.org/10.1016/j.coastaleng.2015.11.010

Mulia IE, Gusman AR, Satake K (2017a) Optimal design for placements of tsunami observing systems to accurately characterize the inducing earthquake. Geophys Res Lett. https://doi.org/10.1002/2017GL075791

Mulia IE, Inazu D, Waseda T, Gusman AR (2017b) Preparing for the future Nankai trough tsunami: a data assimilation and inversion analysis from various observational systems. J Geophys Res Ocean 122:7924-7937. https://doi.org/10.1002/2017JC012695

Mulia IE, Gusman AR, Williamson AL, Satake K (2019) An optimized array configuration of tsunami observation network off southern java, Indonesia. J Geophys Res Solid Earth 124:9622-9637. https://doi.org/10.1029/2019J B017600

Mulia IE, Satake K (2020) Developments of tsunami observing systems in Japan. Front Earth Sci. https://doi.org/10.3389/feart.2020.00145

Mulia IE, Ishibe T, Satake Ket al (2020) Regional probabilistic tsunami hazard assessment associated with active faults along the eastern margin of the Sea of Japan. Earth Planets Space 72:123. https://doi.org/10.1186/s4062 3-020-01256-5

Murphy S, Scala A, Herrero A et al (2016) Shallow slip amplification and enhanced tsunami hazard unravelled by dynamic simulations of megathrust earthquakes. Sci Rep 6:1-12. https://doi.org/10.1038/srep35007

Navarrete P, Cienfuegos R, Satake K et al (2020) Sea surface network optimization for tsunami forecasting in the near field: application to the 2015 Illapel earthquake. Geophys J Int 221:1640-1650. https://doi.org/10.1093/ gij/ggaa098

Nikkhoo M, Walter TR (2015) Triangular dislocation: an analytical, artefact-free solution. Geophys J Int 201:1119-1141. https://doi.org/10.1093/gji/ggv03 5

Nishikawa T, Matsuzawa T, Ohta K et al (2019) The slow earthquake spectrum in the Japan Trench illuminated by the S-net seafloor observatories. Science 365:808-813. https://doi.org/10.1126/science.aax5618

Polster A, Fabian M, Villinger H (2009) Effective resolution and drift of paroscientific pressure sensors derived from long-term seafloor measurements. Geochem Geophys Geosyst 11:6. https://doi.org/10.1029/2009GC002532

Saito T, Kubota T (2020) Tsunami Modeling for the Deep Sea and Inside Focal Areas. Annu Rev Earth Planet Sci 48:121-145. https://doi.org/10.1146/ annurev-earth-071719-054845

Saito T, Tsushima H (2016) Synthesizing ocean bottom pressure records including seismic wave and tsunami contributions: Toward realistic tests of monitoring systems. J Geophys Res Solid Earth 121:8175-8195. https:// doi.org/10.1002/2016JB013195

Satake K (1987) Inversion of tsunami waveforms for the estimation of a fault heterogeneity: method and numerical experiments. J Phys Earth $35: 241-254$

Satake K (1989) Inversion of tsunami waveforms for the estimation of heterogeneous fault motion of large submarine earthquakes: the 1968 Tokachi-oki and 1983 Japan Sea earthquakes. J Geophys Res Solid Earth 94:5627-5636. https://doi.org/10.1029/JB094iB05p05627

Satake K, Fujii Y, Harada T, Namegaya Y (2013) Time and Space Distribution of Coseismic Slip of the 2011 Tohoku Earthquake as Inferred from Tsunami Waveform Data. Bull Seism Soc Am 103:1473-1492

Sepúlveda I, Liu PLF, Grigoriu M, Pritchard M (2017) Tsunami hazard assessments with consideration of uncertain earthquake slip distribution and location. J Geophys Res Solid Earth 122:7252-7271. https://doi. org/10.1002/2017JB014430

Tanioka Y (2018) Tsunami simulation method assimilating ocean bottom pressure data near a tsunami source region. Pure Appl Geophys 175:721-729. https://doi.org/10.1007/s00024-017-1697-5

Tanioka Y (2020) Improvement of near-field tsunami forecasting method using ocean-bottom pressure sensor network (S-net). Earth Planets Space 72:132. https://doi.org/10.1186/s40623-020-01268-1

Tsushima H, Hino R, Fujimoto H et al (2009) Near-field tsunami forecasting from cabled ocean bottom pressure data. J Geophys Res 114:B06309. https://doi.org/10.1029/2008JB005988

Tsushima H, Hirata K, Hayashi Y, et al (2012a) Effect of offshore tsunami station array configuration on accuracy of near-field tsunami forecast. J Jpn Soc Civil Eng, Ser. B2 (Coastal Engineering), 68(2):I_211-I_215. https://doi. org/https://doi.org/10.2208/kaigan.68.I_211

Tsushima H, Hino R, Tanioka Y et al (2012) Tsunami waveform inversion incorporating permanent seafloor deformation and its application to tsunami forecasting. J Geophys Res 117:B03311. https://doi.org/10.1029/2011 J B008877

Wallace LM, Araki E, Saffer D et al (2016) Near-field observations of an offshore Mw 6.0 earthquake from an integrated seafloor and subseafloor monitoring network at the Nankai Trough, southwest Japan. J Geophys Res Solid Earth 121:8338-8351. https://doi.org/10.1002/2016JB013417

Wang Y, Satake K, Sandanbata O et al (2019) Tsunami data assimilation of cabled ocean bottom pressure records for the 2015 Torishima Volcanic Tsunami Earthquake. J Geophys Res Solid Earth 124:10413-10422. https ://doi.org/10.1029/2019JB018056

Wang Y, Heidarzadeh M, Satake K et al (2020) A tsunami warning system based on offshore bottom pressure gauges and data assimilation for Crete Island in the Eastern Mediterranean Basin. J Geophys Res Solid Earth 125:e2020JB020293. https://doi.org/10.1029/2020JB020293

Weatherall P, Marks KM, Jakobsson M et al (2015) A new digital bathymetric model of the world's oceans. Earth Space Sci 2(8):331-345. https://doi. org/10.1002/2015EA000107

Wells DL, Coppersmith KJ (1994) New empirical relationships among magnitude, rupture length, rupture width, rupture area, and surface displacement. Bull - Seismol Soc Am 84:974-1002

Williamson AL, Newman AV (2018) Suitability of open-ocean instrumentation for use in near-field tsunami early warning along seismically active subduction zones. Pure Appl Geophys 176:3247-3262. https://doi. org/10.1007/s00024-018-1898-6

Williamson AL, Melgar D, Rim D (2019) The effect of earthquake kinematics on tsunami propagation. J Geophys Res Solid Earth 124(11):11639-11650

Yamamoto N, Aoi S, Hirata K et al (2016) Multi-index method using offshore ocean-bottom pressure data for real-time tsunami forecast. Earth Planet Space 68:128. https://doi.org/10.1186/s40623-016-0500-7

Yilmaz M, Migliacio P, Bernard E. (2004) Broadband vibrating quartz pressure sensors for tsunameter and other oceanographic applications. Oceans '04 MTS/IEEE Techno-Ocean '04 (IEEE Cat. No.04CH37600), Kobe 2004, pp. 1381-1387 Vol.3. https://doi.org/10.1109/OCEANS.2004.1405783.

\section{Publisher's Note}

Springer Nature remains neutral with regard to jurisdictional claims in published maps and institutional affiliations. 